\title{
Cidadania nos Currículos Oficiais da Geografia Escolar em Minas Gerais Pós Ditadura Militar
}

\author{
Citizenship in the School Geography's Official Curricula in Minas Gerais Post Military \\ Dictatorship
}

\author{
Naiemer Ribeiro de Carvalho \\ Doutoranda em Geografia, UFMG, Brasil \\ naiemer@yahoo.com.br
}

\begin{abstract}
Resumo
Este artigo propõe investigar no currículo oficial nacional, os Parâmetros Curriculares Nacionais PCN (1998 e 1999), e nos currículos estaduais de Minas Gerais (1987 e 2007), a presença ou não do tema "cidadania" na disciplina de Geografia e as noções de cidadania veiculadas pelos mesmos. Dentro desta perspectiva, também observaremos nos currículos se as temáticas e conteúdos relacionados ao período da Ditadura Militar (1964-1985) aparecem e de que forma. Partimos da noção de inscrição (PEREIRA, 2015) para a analisar os currículos sob essa perspectiva e buscamos compreender o papel da presença/ausência desse tema na disciplina e a construção de uma cidadania democrática. Optamos pela leitura dos currículos e análise da ocorrência das palavras "cidadania", "ditadura militar", "identidade" à luz dos referenciais teóricos e históricos utilizados. Pudemos perceber as mudanças das concepções de cidadania e identidade e uma inscrição frágil da ditadura militar.
\end{abstract}

Palavras-chave: Cidadania; Currículo; Geografia Escolar; Ditadura Militar; História.

\begin{abstract}
The present essay aims to investigate, among the national official curriculum of Brazil, the Parâmetros Curriculares Nacionais - PCN (1998 and 1999), and in the official curricula of the state of Minas Gerais (1987 and 2007), the presence - or absence - of "citizenship" as a subject-matter, in Geography, and the notion and concepts of "citizenship" lodged by these documents. Under this perspective, it will be observed, in the curricula, if the themes and contents related to Military Dictatorship (1964-1985) are present and how they are brought forward. It was used the notion of "markings" (PEREIRA, 2015) as a starting point to analyse the curricula, under this perspective, and to comprehend the role of presence/absence of the theme in the subject and in the construction of a democratic citizenship. It was chosen to read the curricula and to analyse the occurrence of the terms "citizenship", "Military Dictatorship" and "identity" under the perspective of the theoretical and historical references used. As a result, it was noticed the changing of the conception of "citizenship" and "identity", and a faint marking of the Military Dictatorship.
\end{abstract}

Keywords: Citzenship; Curriculum; School Geography; Military Dictatorship; History

\section{INTRODUÇÃO}

Este artigo propõe investigar no currículo oficial nacional, os Parâmetros Curriculares Nacionais - PCN (1998 e 1999), e nos currículos estaduais de Minas Gerais (1987 e 2007), a 
presença ou não do tema "cidadania" na disciplina de Geografia e as noções de cidadania veiculadas pelos mesmos. Dentro desta perspectiva, também observaremos nos currículos se as temáticas e conteúdos relacionados ao período da Ditadura Militar (1964-1985) aparecem e de que forma. Partimos da noção de inscrição (PEREIRA, 2015) para a analisar os currículos sob essa perspectiva e buscamos compreender o papel da presença/ausência desse tema na disciplina e a construção de uma cidadania democrática ${ }^{1}$. A noção de inscrição será utilizada a partir dos sentidos mobilizados pela temática nos currículos:

...como ponto de partida, apresentamos alguns dos sentidos que atribuímos a eles.
Inscrição: marca, selo, cicatriz, elaboração, sobrevivência, persistência, permanência,
impressão e fixação. Não inscrição: sombra, branco, vazio, nevoeiro, apagamento,
repressão, invisibilidade e silenciamento. Negação: contestação da realidade, fato ou
acontecimento que pode levar à dissimulação, à falsificação, à fantasia, à distorção e ao
embaralhamento. Em geral, percebemos uma dissimulação e uma distorção da factualidade
que, ou procura negar o poder de veto das fontes, ou fabrica uma retórica com base em
"provas" imaginárias e/ou discutíveis/ manipuladas. Revisionismo: interpretação livre que
não nega necessariamente os fatos, mas que os instrumentaliza para justificar os combates
políticos do presente a fim de construir uma narrativa "alternativa" que, de algum modo,
legitima certas dominações e violências. Negacionismo: radicalização da negação e/ou do
revisionismo. Falsificação do fato." (PEREIRA, 2015, p. 865-6)

O período da redemocratização é um período extremamente próximo, ainda repercute nos dias atuais. Analisamos este período a partir do recorte da consolidação de uma cultura política democrática na educação, na geografia escolar. É inegável que nos últimos anos temos vivido conflitos e demandas de reformulação dos valores e princípios democráticos, até então considerados pelas gerações que se formaram a partir daí, como algo natural, pois pouco viveram do contraste com o período ditatorial.

Sobre esta contradição, Fonseca (1995) afirma que a "história oficial" tentaria ocultar, invisibilizar e homogeneizar os processos sociais, mas não conseguiria excluí-los da memória coletiva pois existem outros agentes como a família, mídia, comunidade, etc. Além disso, há o que Pereira (2015) denomina de guerra de memória, uma disputa sobre a versão dos fatos que se tornaria mais amplamente conhecida e até mesmo aceita. A memória coletiva pode ter implicações e permanências em diversos âmbitos, mas é inegável o papel de alguns atores, especialmente os institucionais, como é o caso da escolarização e dos currículos oficiais, que de certa forma induzem e direcionam o processo da memória e do ocultamento, mas para tal:

A veiculação destes valores e concepções, nestes programas, revelam, entretanto, um contexto histórico em que o discurso institucional encontra "ressonância", ou seja, é "aceito" pelos sujeitos históricos, no caso, os especialistas, detentores do saber e do poder de dizer o que deveria ou não ser transmitido na escola fundamental. (FONSECA, 1995, p. 70)

\footnotetext{
${ }^{1}$ Neste artigo não trataremos dos aspectos pedagógicos gerais ou conceituais específicos da geografia escolar em cada um dos currículos. Tal tarefa refere-se a outro trabalho, em desenvolvimento. O objetivo da análise está delimitado aos aspectos apontados.
} 
A memória, segundo Traverso (2007), seriam as representações sociais coletivas, estruturas das identidades sociais. No caso da Ditadura Militar e do período analisado, trabalhamos com a hipótese de que há um silenciamento sobre a temática nos currículos de Geografia, por algumas razões tais como: a mencionada "aceitação" dos sujeitos históricos das atrocidades e crimes contra a humanidade cometidos no período; a política de conciliação adotada no período da redemocratização, como por exemplo no caso da Anistia que foi ampla e irrestrita, ou seja, para as vítimas e para os algozes; a dificuldade em se trabalhar com temáticas da história recente na escola; a falta de materiais didáticos para a utilização em sala de aula e alta demanda de diversos conteúdos anualmente no currículo escolar. Nesse sentido, Traverso (2007) defende que a História, enquanto um campo do saber, deve se emancipar da memória. O esforço da historiografia é o do distanciamento crítico, não o da negação: "Sua tarefa não consiste em suprimir a memória pessoal, individual e coletiva, mas de inscrevê-la em um conjunto histórico mais vasto. (TRAVERSO, 2007, p. 77)

Para a geografia escolar, tais questões também perpassam seus conteúdos. Destacamos a importância da presença do período da Ditadura Militar em suas diversas possibilidades e relações temáticas para que, através dessa leitura possamos refletir sobre o passado e interpretar a realidade atual onde questões derivadas desta problemática, como revisionismos e negacionismo, estão à tona inclusive nos processos de construção dos currículos e do cotidiano das escolas. É o que Pereira (2015) denominou de processos de inscrição, não inscrição e inscrição frágil que no Brasil ainda estaria em processo de construção, passando sutilmente de uma fase de não inscrição para uma inscrição frágil atualmente.

Os currículos oficiais analisados foram:

- $\quad$ Programa de Geografia de $1^{\circ}$ e $2^{\circ}$ grau do Estado de Minas Gerais (1987): chamaremos de Programa de 1987;

- Parâmetros Curriculares Nacionais de Geografia - Ensino Fundamental (1998): PCN do Ensino Fundamental;

- Parâmetros Curriculares Nacionais de Geografia - Ensino Médio (2000): PCN do Ensino Médio;

- Conteúdos Básicos Comuns de Geografia do Estado de Minas Gerais (2007): CBC.

Tal movimento pretende captar as nuances pelas quais foram passando a noção de cidadania e seu processo de construção na escola e a abordagem da temática da Ditadura Militar.

\section{GEOGRAFIA ESCOLAR E CURRÍCULOS OFICIAIS}


Historicamente, a constituição da geografia enquanto ciência, se deu primeiramente e em grande parte devido a sua constituição enquanto disciplina escolar ${ }^{2}$. A institucionalização da geografia enquanto disciplina escolar antecede a sua institucionalização acadêmica em pelo menos um século no Brasil. Sendo assim, a geografia escolar deu sustentação para a sistematização e institucionalização da geografia e sua existência era diretamente relacionada à formação da nacionalidade ${ }^{3}$.A discussão sobre a finalidade do ensino de geografia escolar e da própria escola pública está historicamente localizada no momento da formação dos Estado-Nação ${ }^{4}$, e isto possui implicações e vinculação às ideologias nacionais ${ }^{5}$.

As disciplinas escolares têm em grande parte seus currículos regulados, direta ou indiretamente pelo Estado, e a inclusão de conteúdo ou a adoção de novas metodologias em geral refletem disputas e conflitos não só no âmbito acadêmico, mas também no âmbito político e social ${ }^{6}$.

Nessa perspectiva, outra noção perpassa esse discurso, a noção de cidadania, também se transformou com o passar dos tempos e na atualidade assume nuances globalistas e ao mesmo tempo locais. A noção de cidadania também cumpre o papel de passar certa neutralidade ao discurso nacionalista que nesse período talvez desejasse um distanciamento do patriotismo exaltado e por vezes ufanista, disseminado durante o período da ditadura militar. Além disso, não podemos analisar essas noções de forma ingênua e utilitarista, pois de alguma forma elas fazem parte de um escopo ideológico que justifica a existência do estado como forma de organização social.

A noção de cidadania se transformou sendo que, desde o Império até a Primeira República perpassa a ideia da construção da nacionalidade brasileira (CARVALHO, 2012), no período do Estado Novo e o período democrático que se segue centra-se no valor do trabalho para o engrandecimento do cidadão e da Pátria (ABREU, 2008; SILVA, 2015), e no período militar, a educação cívica adquire contornos mais institucionalizados e explícitos, pois extinguem-se as disciplinas de História e Geografia no ensino do $1^{\circ}$ grau e em substituição é instituído os Estudos Sociais e são criadas as disciplinas de Educação Moral e Cívica - EMC, e Organização Social e Política Brasileira - OSPB. Segundo Abreu (2008) a centralidade do discurso da formação cívica

\footnotetext{
${ }^{2}$ Rachel Pereira destaca que a geografia acadêmica só teria sido institucionalizada pois serviria como suporte de produção de materiais e de formação de professores, do que propriamente como produção científica. A autora ressalta que a permanência da geografia enquanto disciplina se deveu mais a razões pedagógicas e ideológicas do que científicas (PEREIRA, 1993, p.44). O que não significa afirmar que não houvesse produção de conhecimento geográfico a nível das práticas estatais e mesmo do ensino anteriormente à institucionalização. Ressalta-se aqui o processo de constituição do campo científico e institucionalização.

${ }^{3}$ A relação da geografia e da geografia escolar com a construção da nação está bem documentada, descrita e analisada em: CARVALHO, 2012; MORAES, 1998; PEREIRA, 1993; ROCHA, 1994; VLACH, 1984; entre outros.

${ }^{4}$ Sobre Estado-Nação: GUIBERNAU, 1997; HOBSBAWN, 2008; HOBSBAWN, RANGER, 2008; LACOSTE, 1993; entre outros.

${ }^{5}$ A ideologia poderia ser o conceito que nos auxiliaria a compreender este processo de formação de subjetividades que estão vinculadas a grupos maiores e classes hegemônicas que por vezes não refletimos sobre elas. Sobre ideologia nos referenciamos em: EAGLETON, 1997; e THERBORN, 1991.

${ }^{6}$ Sobre o estudo das disciplinas escolares e os currículos nos referenciamos nas leituras de: Andre Chervel (1990) e Ivor Goodson (1995)
} 
estava relacionada à segurança nacional, fortalecimento do Estado e desenvolvimento econômico. Uma primeira aproximação com as noções de cidadania relacionadas aos discursos estatais vinculados nas escolas e na geografia escolar através dos currículos oficiais no período pós Ditadura Militar, incluindo o período de redemocratização, é o que nos interessa neste estudo.

Embora tenha-se o marco da Constituição de 1988, o processo de regulamentação das leis em torno da educação inicia-se anteriormente e perpassa os fatos políticos, mantendo certa continuidade, claramente influenciada pelo sistema político vigente. Consideraremos a Lei de Diretrizes e Bases da Educação Nacional - LDB, de 1961 (Lei no 4.024/61) um marco importante no processo de democratização da educação e a LDB de 1971 (Lei no 5.692/71) em seus desdobramentos:

\begin{abstract}
A partir da primeira lei de Diretrizes e Bases da Educação Nacional de 1961, consolidou-se no sistema de ensino brasileiro um formato de currículo baseado, em parte comum e obrigatória, no ensino fundamental e médio, complementada por uma parte diversificada, que se torna particularmente expressiva neste último nível. a unidade do ensino propiciada pelo núcleo comum obrigatório, ainda que revestida de um caráter bastante formal - visto que se limita apenas à indicação de matérias e não a uma especificação dos conteúdos tem, mesmo assim, funcionado como uma espécie de passaporte democrático." (BARRETO, 1998, p. 22)
\end{abstract}

A LDB de 1961 cria um núcleo comum obrigatório das disciplinas, gerando um debate nacional neste período, mas para as disciplinas de Geografia e História é a partir da LDB de 1971 que se colocam alterações importantes devido à substituição das mesmas na maior parte do currículo escolar da época:

O ensino de história e geografia foi substituído por Estudos Sociais nas séries do ensino primário e do $1^{\circ}$ grau durante os anos 1970, com a vigência da Lei $n^{\circ}$. 5692/71. Antes disso, em 1969, foi criado o curso de Licenciatura curta em Estudos Sociais que habilitava professores para lecionar as disciplinas das Ciências Sociais. A OSPB foi criada em 1969 pelo Conselho Federal de Educação - CFE, com o argumento de que não existia, à época, uma disciplina similar, ressaltando a necessidade de formação cívica dos estudantes. (ABREU, 2008, p. 11)

Devido à essas legislações e da criação também em 1969 da disciplina Educação Moral e Cívica, as reformulações curriculares ocorridas durante a ditadura militar tiveram um caráter notadamente ideológico, também nos conteúdos implícitos em disciplinas tradicionais como a Geografia e a História.

O movimento de renovação curricular começou a ocorrer durante o processo de redemocratização, especialmente após 1982, quando são liberadas as primeiras eleições diretas para governadores dos estados. As regiões Sul e Sudeste tomam frente nesse processo especificamente por elegerem governos de oposição à ditadura militar (BARRETO, 1998, p. 7).

O contexto de redemocratização trazia à tona e ao debate público questões sobre o que se delinearia como democracia enquanto o novo sistema político e questões além da esfera estatal, o 
que seria a participação democrática no sentido da ampliação do exercício da cidadania e da construção da própria noção do que deveria ser essa cidadania democrática.

Segundo Barretto (1998), as discussões sobre a construção dessa nova noção de cidadania tomaram uma importância maior na escola, pois seu papel seria destacado enquanto um espaço de exercício da cidadania, sendo a educação um direito amplo; e também do caráter social da produção do conhecimento e da promoção de uma formação crítica, capaz de habilitar os sujeitos para esse exercício e para a transformação social. Assim, tornava-se urgente recuperar a relevância social dos conteúdos ensinados em contraposição ao tecnicismo da primeira metade de 70 e às teorias críticas sobre o conhecimento como instrumento de dominação:

\footnotetext{
Essas experiências contribuem para consolidar a concepção de que a própria educação deve traduzir-se em direito de cidadania e ao mesmo tempo, deve municiar a população com um instrumental que lhe permita ser mais efetiva nas suas lutas emancipatórias. O conceito de cidadania passa a expressar mais fortemente a intenção de participação ativa dos cidadãos nos assuntos referentes aos interesses comuns e assume clara associação com a efetivação dos direitos sociais (BARRETO, 1998, p. 13).
}

Em contraposição ao viés tecnicista e economicista do período anterior, com uma educação voltada para a preparação para o mercado de trabalho, a tarefa principal da escola passa a ser essencialmente política: "Cidadania e democracia aparecem, pois, como corolários um do outro, somente passíveis de concretização quando se instala na sociedade um diálogo entre iguais." (BARRETO, 1998, p. 14)

\section{MINAS GERAIS: PROCESSO DE CONSTRUÇÃo DAS PROPOSTAS CURRICULARES NO PERÍODO DE REDEMOCRATIZAÇÃo E PÓS DITADURA MILITAR}

O processo de construção do Programa de Geografia e de História de $1^{\circ}$ e $2^{\circ}$ grau do Estado de Minas Gerais de 1987, iniciou-se bem antes da publicação. Em 1984, no $1^{\circ}$ Congresso Mineiro de Educação, os professores presentes teriam reivindicado a reformulação curricular no estado. Em setembro de 1986, a Secretaria de Estado da Educação de Minas Gerais - SEE/MG, lançou uma chamada para encontros regionais e estaduais com professores de todas as áreas para elaboração de novas propostas curriculares para o $1^{\circ}$ grau (FONSECA; DÂNGELO, 1989, p. 241). Na introdução do Programa de Geografia para o $1^{\circ}$ e $2^{\circ}$ graus este processo foi relatado (MINAS GERAIS, 1987, p. 27).

Embora aparentemente construída em debates, os registros de manifestações de professores relatam um processo onde apenas alguns professores foram convidados a participar, não havendo ampla divulgação e nem a preocupação em permitir o tempo de participação na jornada dos professores (FONSECA; DÂNGELO, 1989, p. 241). 
O tempo para a preparação não foi alterado nem com a mudança de governador, e em 1987 o novo currículo já chegava nas escolas. É relatado também que nem os livros didáticos tiveram tempo de acompanhar a mudança, pois foram encomendados ao Programa Nacional do Livro Didático - PNLD, em 1986 e continham os currículos antigos como parâmetros da avaliação (FONSECA; DÂNGELO, 1989, p. 242). A proposição de novos currículos já se inicia em meio a conflitos e embates de ordem política e reflete a forma como se dá o processo a nível de Estado.

Maria Conceição Lemos (1997) então coordenadora de Geografia do Laboratório de GeoHistória do Centro de Referência do Professor, da Secretaria de Educação do Estado de Minas Gerais, publicou nos anais do III Encontro Estadual de Geografia de Minas Gerais, um resumo no qual comenta as abordagens bem sucedidas e as falhas das propostas curriculares estaduais de geografia de 1986 (publicada em 1987) e de 1993. Segundo a autora, a proposta de 1987 teria avançado as metodologias pedagógicas, superando seu "viés descritivo e fotográfico", e colocando os homens enquanto sujeitos históricos capazes de transformação, mas estaria ainda centrado no "comportamento de caráter valorativo permeando a proposta sem objetivar o estudo geográfico em termos espaciais" (LEMOS, 1997, p. 126), o que poderia significar um viés moral ainda presente na disciplina.

Já em relação a proposta de 1993, a qual não tivemos acesso, Lemos (1997, p. 127) destaca que houveram sérios problemas de coerência internos, sendo que alguns trechos contradizem a proposta apresentada. No entanto, levanta o que considera seu ponto forte:

Os conteúdos temáticos sugeridos, estão organizados cientificamente através de etapas
móveis, que levam em consideração a fase cognitiva do educando, sua sensibilidade e o
meio social em que está inserido, tornando o aprendizado uma conquista pessoal e ao
mesmo tempo social e coletiva. tal enfoque cumprindo os objetivos propostos leva a criança
a desenvolver habilidades e processar conhecimentos para uma decodificação crítica e
criativa da realidade do mundo no qual vive, percebe e concebe, numa perspectiva que
considera o Espaço como objetivo de Ciência geográfica.
Essa visão tem como meta a instrumentalização do aluno para o exercício da cidadania.
Portanto a proposta curricular de geografia SEE/MG pelo seu avanço teórico-metodológico,
contempla a Geografia como Ciência Social, comprometida com a cidadania (LEMOS,
1997, p. 127).

De fato, algumas questões teóricas e metodológicas deveriam ser aprimoradas, principalmente considerando-se o contexto em que surge a primeira proposta, que colocava certo tom de urgência à reformulação curricular, visto que o período ao qual se pretendia desvincular tratava-se de uma ditadura militar com sérias implicações ideológicas para as disciplinas (que inclusive foram substituídas na grade curricular) e para os conteúdos (marcados pela ideologia hegemônica então vigente). Sobre essa a reformulação de 1992, Moraes (1998) analisa:

Por ser o resultado de um segundo processo de alteração das orientações curriculares em menos de uma década, vale iniciar a análise das propostas pela avaliação ali desenvolvida acerca das limitações e equívocos identificados na proposição anterior, e que justificam sua 
própria realização. Observa-se, de imediato, que a crítica realizada é profunda, tocando em pontos basilares, mas suficientemente diplomática para colocar a proposta objeto de renovação como "um sensível avanço em relação às propostas anteriores" (Doc. I p. 139). Ela define seu próprio trabalho como partindo das "dificuldades encontradas na proposta de 1986" e avalia a nova proposição obtida como "em parte baseada na anterior, porém, mais ampla e aliada a mecanismos novos de implantação (Doc. 2, p. 5) (MORAES, 1998, p. 183).

Assim sendo, assume-se uma certa continuidade a ser verificada, tendo em posse a referida proposta. Para fins deste artigo, consideremos a avaliação realizada por Moraes (1998), pois acreditamos trazer elementos importantes para considerações referentes à proposta de 1986/7 e à proposta de 1992/3. É o caso da concepção de escola e seu papel na construção da cidadania. Segundo Moraes (1998), a visão da escola como tendo "um papel redentor, considerando-a capaz de promover a transformação social" (MORAES, 1998, p. 183) é deslocado para uma visão da escola como um "papel de mediação" na sociedade, ou seja, a escola possui uma dinâmica similar à da sociedade, não devendo ser considerada ou mera reprodutora de ideologias, ou produtora de mudanças sociais, pois "a escola é parte da sociedade, logo reproduz a estrutura social ao mesmo tempo que a modifica (Doc. 2, p. 6 apud MORAES, 1998, p. 183). A crítica à proposição anterior aparece também nos objetivos da proposta de 1992:

O documento número 2 apresenta os posicionamentos mais básicos de forma clara: "Permitir a todos os alunos da escola pública estadual a apropriação do patrimônio científico, cultural e artístico, dotando-os de instrumentos capazes de operar a democratização da sociedade" (p.7). Busca-se, assim, a universalização desse patrimônio que, em seu conteúdo básico é definido nos seguintes termos: "São conhecimentos considerados indispensáveis ao convívio do sujeito com sua realidade, ao enfrentamento dos desafios que lhe são apresentados no cotidiano e à promoção de mudanças em seu meio. O domínio desses conhecimentos é, pois, condição fundamental para a construção da cidadania (p.8) (MORAES, 1998, p. 185).

Pelo fato ter sido juntamente com a Geografia, substituída pelos Estudos Sociais no $1^{\circ}$ grau, a História, como aponta Bittencourt (1998), apresentou similaridades no processo de construção. Os objetivos do ensino de História e sua permanência são questionados num contexto de transformações crescentes na sociedade, tendo como centralidade a globalização e os avanços tecnológicos. Identificado por Bittencourt (1998, p. 144) como a questão da formação da identidade. Nesse contexto a formação de uma identidade nacional pareceria deslocada e imporia a discussão sobre quais os sentidos de se ensinar a História, questão também colocada para o ensino de Geografia.

Outra similaridade com a Geografia (MORAES, 1998) é a ausência de referências teórico e metodológicas na elaboração dos currículos da década de 80, sendo que algumas sequer mencionam as referências, apenas elencam os conteúdos, selecionados sem critérios ou ao menos sem critérios explícitos. No caso do Programa de Minas Gerais de 1987, é possível perceber sua singularidade 
tanto na forma quanto em seu conteúdo, organizado em eixos temáticos. Ali também se encontram as referências bibliográficas utilizadas (MINAS GERAIS, 1987, p. 39-42).

Assim como na proposta de Geografia, há a presença de um discurso recorrente sobre uma formação crítica, formação política do cidadão, que Bittencourt (1998) identifica como objetivos antigos, permanências no ensino de História. As mudanças estariam centradas na formação de sujeito histórico, de um cidadão crítico, mas para a autora, tais objetivos não seriam coerentes com as propostas teóricas e metodológicas apresentadas. A proposta de Minas Gerais seria baseada na história-problema desde então, e a pergunta motivadora seria: “Que país é este?”.

Bittencourt (1998) levanta dois pontos importantes ao analisar as bibliografias das propostas curriculares estaduais: 1. Livros didáticos foram utilizados como referências; 2. Algumas propostas serviram de parâmetros para as outras (inclusive de Estudos sociais); a proposta de Minas Gerais de 1986/7 é citada nesse caso. Interessante também observar os dois tipos de bibliografia encontrados: 1. dos textos utilizados pelos autores para a elaboração, mais acadêmicos; e 2. de textos voltados para os professores, seja o considerando um intelectual, sejam textos paradidáticos, simplificadores.

\section{A LEI DE DIRETRIZES E BASES DA EDUCAÇÃO DE 1996 E OS PCN}

Como destacado anteriormente, esse movimento de renovação curricular de base democrática, foi iniciado na década de 1980, especialmente nos estados onde governadores da oposição foram eleitos. A relação da construção de um currículo comum nacional com o processo de renovação curricular dos Estados está diretamente mencionada no Volume 1 dos PCN, na Introdução ${ }^{7}$ :

\footnotetext{
O processo de elaboração dos Parâmetros Curriculares Nacionais teve início a partir do estudo de propostas curriculares de Estados e Municípios brasileiros, da análise realizada pela Fundação Carlos Chagas sobre os currículos oficiais e do contato com informações relativas a experiências de outros países. Foram analisados subsídios oriundos do Plano Decenal de Educação, de pesquisas nacionais e internacionais, dados estatísticos sobre desempenho de alunos do ensino fundamental, bem como experiências de sala de aula difundidas em encontros, seminários e publicações (BRASIL, 1997, p. 15).
}

O processo iniciado nos estados também ressoa no processo de redemocratização da sociedade e estará representado na elaboração da Constituição Federal de 1988, a chamada “Constituição Cidadã”, e também da nova LDB, que já se encontrava em curso, mas seria concretizada apenas em 1996:

\footnotetext{
7 O estudo encomendado para a Fundação Carlos Chagas posteriormente foi publicado em livro, referências que utilizamos aqui: BARRETO (1998), BITTENCOURT (1998) e MORAES (1998).
} 
Na CF de 1988 é possível encontrar uma série de artigos referentes direta ou indiretamente a uma formação básica comum, dimensão esta garantida após intensa discussão entre atores políticos que, durante a Assembleia Nacional Constituinte, tinham polemizado sobre questões curriculares.

Por meio desses artigos, a CF fixa conteúdos mínimos para o ensino fundamental dentro dos princípios de igualdade e de diversidade, com vistas a assegurar uma formação básica comum e a coexistência de registros culturais diferenciados, em qualquer proposta curricular e nos diferentes níveis de governo e nas unidades escolares.

O prosseguimento da discussão curricular deu-se em torno da LDB que tramitava no Congresso desde 1988. A nova LDB reafirmou a CF ao considerar ser incumbência da União, em colaboração com estados, Distrito Federal e municípios, estabelecer diretrizes para nortear os currículos e seus conteúdos mínimos de forma que se assegure a formação básica comum (art. 9º IV) (BONAMINO; MARTÍNEZ, 2002, p. 370).

Após mais de uma década de discussões e propostas estaduais de reformulações curriculares, foi elaborada a LDB de 1996 (Lei no 9.394/96) e em seguida os Parâmetros Curriculares Nacionais- PCN, em 1998 do Ensino Fundamental e em 1999 do Ensino Médio, nos quais poderemos perceber a síntese dessas discussões e as principais alterações em suas linhas temáticas e de indução. Em ambos, como no artigo $9^{\circ}$ da LDB está presente a necessidade de definição da:

... competência da União, em colaboração com os estados, Distrito Federal e Municípios, diretrizes que nortearão seus currículos e os conteúdos mínimos, de modo a assegurar uma formação básica comum (apud BONAMINO; MARTÍNEZ, 2002, p. 379).

Seu processo de construção também sofreu críticas sobre a ausência de participação dos professores e das associações e entidades científicas e/ou profissionais. Rosalina Braga (1997, p. 24) destaca como um ponto favorável nos PCN, seu distanciamento dos Estudos Sociais e uma demarcação das áreas de Geografia e História, porém ainda não incorporaria os avanços existentes nas pesquisas sobre Educação Geográfica no Brasil.

Em relação à noção de cidadania e sua construção na escola, já pode-se perceber alterações nesta proposta em relação às anteriores da década de 1980. Há que se considerar que o contexto de redemocratização tornava as discussões em torno do tema mais acaloradas, mas não significa que houve um desaparecimento da temática, ao contrário, talvez possamos afirmar que houve uma reformulação da proposta no sentido em que o discurso sobre a cidadania e sua construção na escola aparece mais próximo e afinado com teorias e processos pedagógicos vigentes. A própria estrutura dos PCN, baseada na construção de competências e habilidades, mais do que uma grade mínima de conteúdos, nos permitiria essa reflexão.

\section{A ANÁLISE E OS CURRÍCULOS}

Optamos pela leitura dos currículos e análise da ocorrência das palavras "cidadania", "ditadura militar", "identidade" à luz dos referenciais teóricos e históricos citados. A palavra 
"cidadania" e suas derivadas foram escolhidas por acreditarmos concentrar as discussões neste sentido; a "Ditadura Militar" e palavras correlatas foram incluídas pensando na noção da inscrição e de sua influência no debate da cidadania no período; e a palavra "identidade" foi escolhida para tentarmos perceber suas utilizações e adjetivações pensando nas finalidades da disciplina.

Quadro 1 - Ocorrência das palavras analisadas nos currículos de Geografia.

\begin{tabular}{|c|c|c|c|}
\hline Currículo & Cidadania & Ditadura Militar & Identidade \\
\hline $\begin{array}{l}\text { Programa de Geografia de } 1^{\circ} \text { e } 2^{\circ} \text { grau do Estado } \\
\text { de Minas Gerais (1987) }\end{array}$ & $0(10)^{*}$ & 0 & 0 \\
\hline $\begin{array}{l}\text { Parâmetros Curriculares Nacionais de Geografia - } \\
\text { Ensino Fundamental } 5^{\mathrm{a}} \text { a } 8^{\mathrm{a}} \text { séries (1998) }\end{array}$ & 35 & 2 & 28 \\
\hline $\begin{array}{l}\text { Parâmetros Curriculares Nacionais de Geografia - } \\
\text { Ensino Médio (1999) }\end{array}$ & $50(19)^{*}$ & 0 & 47 \\
\hline $\begin{array}{l}\text { Conteúdos Básicos Comuns de Geografia do } \\
\text { Estado de Minas Gerais (2007) }\end{array}$ & $15(7)^{*}$ & 0 & 25 \\
\hline
\end{tabular}

Fonte: elaboração própria com base nos currículos listados.

* Entre parênteses a ocorrência das palavras correlatas.

Seguem abaixo a descrição e comentários sobre as ocorrências em cada um dos documentos analisados:

\subsection{Programa de Geografia de $1^{\circ}$ e $2^{\circ}$ grau do Estado de Minas Gerais (1987)}

O currículo de Geografia de Minas Gerais de 1987 foi inserido na tabela para estabelecermos um parâmetro de comparação. Com o aumento ou não da ocorrência de palavras que pode indicar um aumento da influência de determinadas correntes e concepções em sua elaboração no período, sendo depois reverberado no parâmetro nacional que retorna a influenciar os estados.

Neste documento estão incluídas a $3^{\mathrm{a}}$ e a $4^{\mathrm{a}}$ séries do fundamental, único local onde aparece 10 vezes a palavra correlata à cidadania, “cidadão/cidadãos". Tal fato pode estar relacionado à natureza do ensino nesta etapa da escolarização. Como explicitado pelo próprio documento, os conteúdos de Geografia e História são desenvolvidos em conjunto na perspectiva da "Formação Social e Política":

... torna-se clara a necessidade de o homem assumir seu papel como sujeito capaz de se organizar em grupo, tendo como objetivo a defesa dos interesses coletivos. É fundamental um trabalho inteiramente voltado para enfrentar os conflitos e as contradições, provocar mudanças que se articulem na direção dos reais interesses da população, quebrando esse círculo vicioso.

O motor que impulsiona a mudança dessa situação te, como força geradora, a consciência política e a capacidade de organização da sociedade. A escola é um dos mais importantes 
espaços para a formação social e política do cidadão. Como instituição social criada em função do interesse coletivo, não pode negar esse papel (MINAS GERAIS, 1987, p. 23).

Em nenhum dos programas há menção às palavras "Ditadura Militar" ou correlatas, podendo indicar aqui a questão colocada pelo então tempo presente, o período de redemocratização, quando os processos de renovação dos currículos buscavam reconquistar o espaço perdido pela disciplina no período da ditadura e talvez não tenha buscado esse tipo de enfrentamento, Moraes (1998) identifica questões similares como concessões. Porém a orientação crítica do papel da escola e da formação de sujeitos participativos é claro e repetitivamente aparece em trechos de conteúdos e orientações metodológicas. Por exemplo, o "círculo vicioso" mencionado trecho do programa acima, refere-se à falta de organização da população que não escolhe "bem" (ou indiretamente sequer escolhia) seus representantes. Outra questão que pode se relacionar a esta ausência, é a preferência por trabalhar em eixos conceituais, evitando deliberadamente as listagens de conteúdos pontuais.

A questão de programa centrar-se conceitualmente nos princípios de uma geografia crítica, fica clara nos programas de $5^{\mathrm{a}}$ à $8^{\mathrm{a}}$ séries e também no do $2^{\circ}$ grau:

A perspectiva crítica, na Geografia, preconiza, não a reprodução dos fatos geográficos e dos dados brutos da experiência sensível, não a acumulação de informações sobre um fato e um objeto dados, mas, a aplicação de estruturas conceituais sobre o real, transformando-o. É o relacionamento entre pensamento e realidade que constitui o processo de conhecimento e não, a descrição ou a observação passiva da realidade (MINAS GERAIS, 1987, p. 28).

Percebemos nos programas a intenção em deixar sua posição por uma geografia crítica demarcada, em oposição às disciplinas como a OSPB e EMC - que são recomendadas à extinção e substituição pela Geografia e História (MINAS GERAIS, 1987, p. 29), e também aos Estudos Sociais, sendo os eixos de estudo organizados em torno da relação sociedade/natureza/trabalho e da produção do espaço brasileiro e mundial.

A palavra "identidade" e correlatas não aparecem, e neste caso supomos haver ainda os resquícios das formas passadas presentes nos Estudos Sociais e a fraca difusão desta palavra como um conceito para a educação, principalmente em substituição às ideias de Pátria, Comunidade e similares. Os conteúdos relacionados à Pátria (explicitada como Comunidade mais ampla), Comunidade e Municípios, Estado de Minas Gerais e País buscam trazer a mesma perspectiva de participação na vida coletiva e comunitária enquanto sujeitos ativos neste processo, seja em seu bairro, seja nas eleições dos diversos níveis, articulando os conceitos "homem-sujeito, grupo, espaço, tempo, trabalho, movimento, contradição, conflito, mudança, transformação" (MINAS GERAIS, 1987, p. 22-3) 


\section{2. Parâmetros Curriculares Nacionais de Geografia - Ensino Fundamental $5^{\mathrm{a}}$ a $8^{\mathrm{a}}$ séries (1998) e Ensino Médio (1999)}

Devido às similaridades conceituais das propostas, embora as ocorrências de palavras estejam organizadas separadamente no quadro, trataremos dos dois currículos conjuntamente nesta subseção.

Primeiramente no documento do Ensino Fundamental, a palavra "cidadania" aparece 35 vezes no documento, desde a dedicatória “Ao Professor” (BRASIL, 1998, p. 05) até a penúltima página de texto (BRASIL, 1998, p. 144) e mais uma vez no título de uma das referências bibliográficas (BRASIL, 1998, p. 153). Aparece nos objetivos dos PCN, nos subtítulos dos tópicos de conteúdo da geografia, e no decorrer do texto relacionando o termo à Geografia, seus conteúdos e competências específicos.

A palavra "ditadura" aparece no documento apenas duas vezes: a primeira vez aparece no plural, ditaduras, na página 106 (BRASIL, 1998), "Eixo 2: Um só mundo e muitos cenários geográficos", onde possui um sentido geral, teórico, de combate às ditaduras no mundo; e na página 122 (BRASIL, 1998), num contexto mais histórico e específico do Brasil, porém o parágrafo trata do "atraso" do movimento ambientalista no Brasil devido ao período da ditadura no militar no Brasil, aparece mais como uma menção. Não aparece a palavra "golpe" em nenhum momento do documento. Ao se referir à ditadura militar especificamente como conteúdo, aparece como "regime militar" no tópico "O papel do Estado e das classes sociais e a sociedade urbano-industrial brasileira":

O regime militar que se implantou a partir de 1964 foi a resposta autoritária do Estado legitimado pela cumplicidade da burguesia urbana, e de oligarquias agrárias do país, às reformas pretendidas pelos trabalhadores. Esse regime, alijando qualquer representação política da classe trabalhadora no poder, passou a realizar profundas reformas de caráter conservador. Foi o período do milagre brasileiro. Nem sempre é fácil para o professor analisar e estabelecer suas críticas sobre a natureza e a política que orientou a ocorrência desse "milagre". Porém, é necessário que se reconheçam as profundas transformações que ocorrem com a economia brasileira, mesmo quando sabemos dos sacrifícios que significaram para o trabalhador brasileiro. (BRASIL, 1998, p. 72)

No trecho acima, encontramos uma caracterização do período a partir da concepção de algumas correntes que o denominam ditadura civil-militar. O regime militar é caracterizado como autoritário, mas ao mesmo tempo é denominado de o "milagre brasileiro". A palavra milagre vem em seguida com o uso de aspas, o que poderia indicar certo receio em utilizar a mesma. É ressaltada aqui a questão da economia e do sacrifício do trabalhador brasileiro. A crítica continua no parágrafo que se segue ao citado acima:

Essa "modernização conservadora" foi realizada à custa de um grande endividamento com a entrada maciça de capitais e tecnologias estrangeiras. $\mathrm{O}$ estímulo às exportações foi a estratégia para compensar esse grande endividamento externo e interno gerado pelos 
investimentos como: centrais hidrelétricas, usinas nucleares, infraestrutura urbana, principalmente aquelas ligadas aos sistemas viários urbanos, subsídios às usinas produtoras de álcool (Programa Proálcool) para a produção de combustível para automóveis. Todas essas transformações foram acompanhadas pela forte presença do Estado brasileiro como investidor, por um grande arrocho salarial e repressão policial contra as reinvindicações da classe trabalhadora. Foi durante o regime militar que a Amazônia foi aberta às grandes empresas nacionais e multinacionais e que de forma predatória passaram a realizar os grandes projetos de exploração florestal e mineral da região (BRASIL, 1998, p. 72).

A crítica ao regime militar permanece no âmbito econômico do processo de modernização e das relações internacionais entre estado e corporações e interesses no território. Na ocorrência seguinte, o texto continua a explicação sobre o processo de modernização e explica o porquê da queda do regime:

O conjunto de contradições intrínsecas a esse modelo autoritário adotado pelo Estado brasileiro tornou-se importante diante das novas investidas que começaram a emergir por parte das classes operárias das cidades, assim como dos trabalhadores do campo. Em São Paulo, centro nevrálgico do novo capitalismo, surgiram movimentos de contestação ao regime (BRASIL, 1998, p. 72).

As insatisfações da classe trabalhadora e a frustração da classe média, a cujos anseios o regime não deu continuidade, acabaram por ocasionar, nos anos 80, o desmoronamento desse modelo autoritário de acumulação capitalista no Brasil. Mais recentemente, os movimentos dos sem-terra surgidos no Sul e Sudeste do país, onde as contradições da modernização conservadora revelaram-se de forma mais evidente, levam a pensar no impasse em que o Estado brasileiro se vê mergulhado. A orientação do professor nesse momento será de grande valia para que o aluno compreenda a ideia de impasse como resultado de um processo de contradições nascido das ações políticas das classes dirigentes e passíveis de soluções desde que a sociedade, principalmente a classe trabalhadora, tenha consciência da sua importância nas decisões políticas do Estado.

O processo de democratização pelo qual o Brasil passou após a queda do regime militar nos anos 80 não garantiu ainda a realização de uma verdadeira reforma agrária, soluções para o problema de moradia e de desemprego (BRASIL, 1998, p. 73).

Percebemos que embora seja pouca a ocorrência da palavra relacionada à Ditadura Militar, o tratamento dado à questão é aberto em relação ao seu viés autoritário, aos processos de disputas e conflitos existentes durante e após o período, porém centrada na questão econômica. Desta forma, há uma indicação de inscrição da temática no debate social e escolar em seu período posterior.

A palavra "identidade" aparece 28 vezes ao longo de todo texto, com vários sentidos, desde identidade nacional, identidades regionais na perspectiva do lugar, identidades culturais em sentido amplo, multiculturalista, até identidade das paisagens e regiões, e identidades históricas. Esta multiplicidade de adjetivações pode indicar o aparecimento de concepções identitárias e multiculturais no campo educacional.

Nos PCN do Ensino Médio há uma particularidade em trazer as disciplinas organizadas por áreas, no caso da geografia, na área das Ciências Humanas e suas tecnologias, Parte IV. Para a análise e composição do quadro das palavras, retiramos as partes referentes às disciplinas de História, Sociologia e Filosofia, mantendo apenas a apresentação, o currículo de Geografia e as considerações ao final do documento. Em um primeiro momento, podemos observar que apesar de 
contar com um número de páginas menor, a ocorrência de duas das palavras é bem superior do que no ensino fundamental.

A palavra "cidadania" aparece 50 vezes e as correlatas 19 vezes, totalizando 69 vezes. A perspectiva da cidadania enquanto um exercício e do papel da escola e do currículo disciplinar desenvolvido em competências que auxiliariam este exercício. Seu sentido é expandido além da cidadania política, e é proposta uma cidadania social, destacadamente voltada às relações de trabalho (BRASIL, 2000, p. 12). Esta aproximação mais clara ao mundo do trabalho relaciona-se também à especificidade da faixa etária deste nível de ensino.

As palavras "Ditadura militar" e correlatas não aparecem. Porém, ligada à ideia da cidadania, há questões referentes à justiça e ao direito à memória, uma das categorias relacionadas aos estudos sobre o passado recente.

As palavras “identidade/identidades" aparecem ao todo 47 vezes, relacionadas à construção de princípios éticos, da identidade pessoal e social e como base para a consolidação da formação da cidadania iniciada no Ensino Fundamental (BRASIL, 2000, p. 22) A identidade também se relaciona aos conceitos-chave propostos para a aprendizagem em geografia. Faremos um destaque aqui para os conceitos realçados para o estudo de geografia de modo a compará-los com os apontados pelo Programa de 1987: paisagem, lugar, território e territorialidade, escala, globalização, técnica e redes (BRASIL, 2000, 32-3).

\subsection{Conteúdos Básicos Comuns de Geografia do Estado de Minas Gerais (2007)}

O documento dos CBC de 2007 contempla tanto o Ensino Fundamental (6 $6^{\mathrm{a}}$ a $9^{\mathrm{a}}$ séries) e o Ensino Médio. Optamos por contabilizar as palavras conjuntamente, pois trata-se de um documento único, publicado conjuntamente.

A palavra "cidadania" aparece 15 vezes, sendo que aparece relacionada ao conceito de forma ampla e aos direitos sociais e das outras vezes aparece relacionada aos temas e conteúdo da Geografia, como globalização, meio ambiente e cidadania planetária (que compõe o nome de um dos eixos), principalmente. As palavras derivadas, como cidadão (3 vezes), cidadãos (4 vezes), aparecem em mesmo contexto e em proximidade com a palavra "cidadania". Sobre a questão do ensino de geografia e a construção da cidadania, temos:

O ensino da Geografia, assim como de outras disciplinas, contribui para o desenvolvimento da autonomia, a compreensão dos direitos, dos limites e potencialidades da ciência e da tecnologia e os desdobramentos que tal desenvolvimento trouxe na construção das espacialidades. Para isso, é imperioso aprender a pensar na lógica das redes de relações, no movimento do pensamento complexo para que, ao contextualizar espacialmente os fenômenos e ao conhecer o planeta nas escalas locais, regionais, nacionais e internacionais, essa compreensão abra possibilidades de desenvolvimento de outras lógicas e uma nova ética: ambiental e social. Essa razão atribui substância à cidadania que se faz necessária no processo de globalização incontrolável. Nesse sentido, a geografia pode trazer, para as 
reflexões educacionais, uma dimensão que problematize a lógica do consumo que processa uma sociedade insustentável. Para Milton Santos, esse seria o papel de uma geografia cidadã. Esse é mais um sentido para se ensinar Geografia nas escolas de Educação Básica de Minas Gerais (MINAS GERAIS, 2007, p. 12-3).

Este sentido articula-se com o sentido dado à cidadania e expresso no direito à educação e a educação como formadora de cidadãos conscientes e ativos no mundo de hoje. No entanto, não está explicitada essa noção do papel da escola e da aprendizagem em nenhum ponto do documento, apenas nessa parte onde trata do sentido de ensinar geografia e nas habilidades atitudinais. Os outros sentidos atribuídos, são de uma matriz mais abstrata, relacionada aos conteúdos principalmente de meio ambiente, globalização e consumismo. Neste mesmo tópico sobre o sentido de ensinar geografia, os professores participantes do Projeto de Desenvolvimento Profissional (PDP), que tiveram relação com a construção do CBC, destacam a cidadania associada ao consumo e a sociedades sustentáveis: “Compreensão da relação implícita entre lógica do consumo, consumismo e cidadania, formando atitudes e valores com vistas à construção de sociedades sustentáveis" (MINAS GERAIS, 2007, p. 13). Fala-se também em "formação de atitudes cidadãs" no desenvolvimento das dimensões conceituais e procedimentais (MINAS GERAIS, 2007, p. 14), sendo que a cidadania aparece também nos critérios para a seleção dos conteúdos, situada na dimensão das atitudes:

As atitudes referem-se às manifestações dos valores em construção pelos alunos. Cria, também, situações educativas para o desenvolvimento de uma atitude problematizadora no educando e outras dimensões do ser cidadão em formação, tais como:

- Valorização de políticas públicas democratizadoras de acesso à cidadania e à qualidade de vida;

- Respeito à pluralidade cultural expressa nas manifestações de vestir, falar, festejar;

- Consumo com responsabilidade dos recursos naturais não renováveis, evitando o desperdício dos bens pessoais e coletivos;

- Postura crítica diante do modelo mundial de degradação ambiental (MINAS GERAIS, 2007, p. 18).

Mais à frente, a cidadania almejada ainda aparece adjetivada como "ecocidadania':

Dos 40 tópicos, selecionamos 20 que expressam de forma mais contextualizada a pluralidade da ciência geográfica na atualidade, permitindo compreender o espaço geográfico, com vistas à formação de uma ecocidadania (MINAS GERAIS, 2007, p. 21-2).

No conteúdo a cidadania aparecerá das duas formas, primeiramente relacionada aos direitos sociais:

O eixo temático Geografias do Cotidiano recupera a cotidianidade do lugar, representado pela cidade e o campo, onde ocorrem as relações de trabalho, de cultura e de lazer. Os tópicos selecionados para o CBC são: território e territorialidade; paisagens do cotidiano; cidadania e direitos sociais; lazer; segregação espacial; redes e circulação (MINAS GERAIS, 2007, p. 22).

E em seu sentido relacionado à temática do meio ambiente: 
No eixo temático, Meio Ambiente e Cidadania Planetária, priorizamos no CBC os tópicos: desenvolvimento sustentável; indústria e meio ambiente; cidades sustentáveis; Agenda 21; padrão de produção e consumo, que alinhavam as relações sociedade e natureza nas suas discussões mais contemporâneas de sustentabilidade. Eles indicam percursos dentro de uma nova lógica de cooperação e solidariedade, garantidos por uma legislação ambiental e uma nova ética fundada na responsabilidade socioambiental (MINAS GERAIS, 2007, p. 22).

A “ecocidadania” e a "cidadania planetária” são concepções que podem estar relacionadas às discussões, muito em voga na geografia e na sociedade brasileira desde a década de 1990, sobre as questões ambientais e às discussões dos conceitos e dos efeitos da globalização. Ao mesmo tempo, é uma cidadania que acaba por deslocar e produzir certo apagamento de seu eixo político, concentrando-se mais explicitamente em questões sociais e em posturas individuais, como o consumismo.

A palavra “ditadura" não aparece no documento, nem as palavras de busca correlatas, como militar, regime, autoritário. O que nos parece algo relevante, dado que o documento possui os currículos tanto do nível fundamental quanto do médio.

A palavra "identidade(s)" aparece 25 vezes no documento. Os sentidos mobilizados aqui se aproximam dos sentidos propostos pelos PCN: a construção de identidades em escalas múltiplas, do indivíduo e do grupo, do lugar e do mundo.

\section{CARACTERIZAÇÃO E ELEMENTOS DA CIDADANIA}

A partir da leitura das referências bibliográficas e dos documentos, propusemos e organizamos uma caracterização dos elementos referentes à construção da cidadania nos períodos da Ditadura, redemocratização e pós ditadura.

Elementos da cidadania no período da Ditadura Militar e período anterior:

- Integrar ou ajustar o aluno ao meio social (FONSECA, 1995);

- Cidadania numa perspectiva clássica, associada aos direitos civis e principalmente aos direitos políticos, não inclui outras formas de participação política na sociedade, como por exemplo, através de movimentos sociais (BARRETO, 1998, p. 12).

Ações para a promover a construção dessa cidadania na escola:

- Ensino de história e geografia foi substituído por Estudos Sociais nas séries do ensino primário e do $1^{\circ}$ grau durante os anos 1970, com a vigência da Lei n ${ }^{\circ} .5692 / 71$;

- $\quad$ As disciplinas OSPB e EMC criadas em 1969;

- As equipes técnicas e burocráticas do Estado criaram os currículos e a organizaram as atividades escolares sem a participação dos agentes escolares (FONSECA, 1995, p. 55); 
- Orientação cívica: heróis grandes personalidades, grandes eventos que marcaram a nação;

- Comemoração das datas cívicas.

Noção de cidadania: elementos para a construção da cidadania democrática pós ditadura militar:

- $\quad$ Educação como um direito;

- Caráter social da produção do conhecimento;

- Promoção de uma formação crítica;

- Educação para o exercício da cidadania;

- $\quad$ Educação para a transformação social;

- $\quad$ Direitos humanos;

- Formar o cidadão democrático implica investir na sedimentação no aluno do respeito à diferença, considerando a pluralidade de visões como um valor em si (MORAES, 1998);

- $\quad$ Década de 1980: A escola "um papel redentor, considerando-a capaz de promover a transformação social" (MORAES, 1998);

- Década de 90: escola como um "papel de mediação" na sociedade, ou seja, a escola possui uma dinâmica similar à da sociedade, não devendo ser considerada ou mera reprodutora de ideologias, ou produtora de mudanças sociais, pois "a escola é parte da sociedade, logo reproduz a estrutura social ao mesmo tempo que a modifica" (MORAES, 1998).

Ações para a promover a construção da cidadania na escola:

- Reformulação curricular;

- Recuperar a relevância social dos conteúdos ensinados em contraposição ao tecnicismo;

- $\quad$ Renovação metodológica;

- Aproximação dos conteúdos à realidade do aluno para possibilitar a interpretação da realidade que vive e sua transformação;

- Formação básica comum garantiria condições de igualdade desde que preservasse regionalismos e particularidades;

- Permitir a todos os alunos da escola pública estadual a apropriação do patrimônio científico, cultural e artístico, dotando-os de instrumentos capazes de operar a democratização da sociedade" (MORAES, 1998, p. 7); 


\section{CONSIDERAÇÕES FINAIS}

A geografia é uma disciplina escolar presente desde o início do processo da escolarização no Brasil no século XIX, e demorou décadas para completar seus processos de sistematização e consolidação e adquirir autonomia teórico-metodológica. Neste período próximo da história recente que analisamos, mesmo sendo uma disciplina madura e autônoma, foi reunida à História na disciplina dos Estudos Sociais pela ditadura militar. As disputas por sua autonomia se reiniciaram assim que foi possível, no contexto da redemocratização. Mas ainda podemos perceber que após sua separação, ainda ressoam as finalidades gerais da educação, como propostas pela legislação, e a redefinição, mesmo que parcial, em suas finalidades específicas, sendo que percebemos uma renovação de seu papel na formação da nacionalidade e de uma cidadania.

Em relação à forma de utilização da palavra cidadania, pudemos perceber uma mudança de concepção, relacionada diretamente aos contextos próprios de produção de cada um dos currículos. No contexto do Programa de 1987, percebemos a intenção de incentivar uma cidadania ativa e do papel da escola em sua construção em oposição direta ao contexto da ditadura militar, imediatamente anterior. Ao mesmo tempo, há uma concessão ao processo de redemocratização e no calor do momento, a referência direta à Ditadura Militar é ocultada. Nos PCN as reformas educacionais, ligadas a correntes pedagógicas e a interesses econômicos neoliberais, a estrutura curricular é modificada sob a forma do currículo de competências. Há também um grande peso em relação à importância das atividades econômicas e em especial ao trabalho na vida dos educandos. O exercício da cidadania passa então a ser associado a múltiplas vivências sociais, culturais, pessoais e coletivas dos educandos, extrapolando certa aura de cidadania política de perspectiva clássica, o que isoladamente não significa ganho. E nos CBC, a cidadania apresentada reforça essa noção ampliada da cidadania através das "atitudes cidadãs" e a ampliando ainda para uma “cidadania planetária" e para a questão ambiental através de uma "ecocidadania".

Em relação à inscrição da Ditadura Militar nos currículos, percebemos que apesar de presente, essa presença é tênue, pontual e fragmentada. Ela apresenta uma inscrição frágil, no sentido da elaboração e permanência, aparecendo apenas nos PCN do Ensino Fundamental em 1998. O sentido da cicatriz também pode ser levantado aqui, já que a temática aparece relacionada aos conteúdos da disciplina e não há ocultamento da temática ou distorção dos fatos, aparecendo porém apenas em recortes específicos. Nesta inscrição frágil não foi detectado nenhum tipo de negacionismo ou revisionismo, como em alguns casos quando há a troca da expressão "Golpe Militar" por "Revolução", por exemplo. A ausência nos outros currículos pode estar relacionada ao momento da reabertura política, para o Programa de 1987. Para o CBC de 2007, poderíamos falar 
em sua não-inscrição, no sentido da invisibilização, apagamento e silenciamento da memória e da temática nos currículos do Ensino Fundamental e Médio.

A palavra identidade não aparece no Programa de 1987 em Minas Gerais. Como já dissemos acima, a noção de identificação/identitária, é relacionada à Pátria e à Comunidade, porém o termo em si ainda não estava em voga no ambiente educacional. A partir dos PCN de 1998 e 1999, e reverberando no CBC de 2007, pudemos perceber uma ampliação e extensa adjetivação relacionada à identidade, inclusive em diferentes escalas, do pessoal e do coletivo. Nesse sentido é possível perceber um deslocamento de sentidos e um aprofundamento necessário a ser feito.

Enfim, propusemos aqui uma possibilidade de leitura de documentos a partir de uma conceituação e de seu contexto histórico. As dificuldades presentes nas leituras de documentos oficiais são diversas, assim como suas limitações. No caso dos currículos oficiais, há uma tendência em vê-los apenas como prescrição, como algo descolado das práticas nas salas de aula. No entanto ressaltamos que, embora o elemento da prescrição seja um fato, tal fato não invalida que, para chegar ao documento, tais concepções, ideias e teorias passam por discussões e debates na sociedade e em suas áreas e campos específicos, refletindo ideias e práticas já existentes. Outra questão refere-se à quantidade de políticas públicas associadas à implementação de um currículo oficial, como o PNLD, formação de professores, avaliação da escolarização, dentre outros, acabando por induzir, de alguma forma, suas proposições, concepções e discursos que vão além de uma proposição unicamente conteudística e neutra para as disciplinas, mas carrega em si elementos das finalidades sociais do processo de escolarização da sociedade (CHERVEL, 1990; GOODSON, 1995). A partir deste primeiro movimento de leitura deste processo, poderemos acompanhar seu desenvolvimento nos currículos seguintes, à título de comparação e análise de suas relações com cada contexto específico.

\section{REFERÊNCIAS}

ABREU, V. K. A Educação Moral e Cívica: disciplina escolar e doutrina disciplinar - Minas Gerais (1969-1993). 2008. 102 f. (Mestrado em Educação) - Programa de Pós-graduação em Educação, Universidade Federal de Uberlândia, Uberlândia, 2008.

BARRETTO, E. S. S. Tendências recentes do currículo do ensino fundamental no Brasil. In: BARRETTO, E. S. S. Os currículos do ensino fundamental para escolas brasileiras. Campinas: Autores Associados, 1998.

BITTENCOURT, C. M. F. Propostas curriculares de História: continuidades e transformações. In: BARRETTO, E. S. S. Os currículos do ensino fundamental para escolas brasileiras. Campinas: Autores Associados, 1998.

BRAGA, R. B. Parâmetros Curriculares Nacionais de Geografia: elementos para uma discussão. In: ENCONTRO ESTADUAL DE GEOGRAFIA DE MINAS GERAIS. 3., 1997, Belo Horizonte. Anais... Belo Horizonte: UFMG, 1997. 
BRASIL. Ministério da Educação e do Desporto. Secretaria de Educação Fundamental. Parâmetros Curriculares Nacionais: introdução aos parâmetros curriculares nacionais. Brasília, DF: MEC/SEF, 1997. 126p.

BRASIL. Ministério da Educação e do Desporto. Secretaria de Educação Fundamental. Parâmetros Curriculares Nacionais: terceiro e quarto ciclos do ensino fundamental - geografia. Brasília, DF: MEC/SEF, 1998. 156p.

BRASIL. Ministério da Educação. Secretaria de Educação Média e Tecnológica - SEMTEC. 1999. Parâmetros Curriculares Nacionais para o Ensino Médio. Brasília: MEC/SEMTEC, v. IV.

BONAMINO, A.; MARTÍNEZ, S. A. Diretrizes e Parâmetros curriculares nacionais para o Ensino Fundamental: A participação das instâncias políticas do Estado. Educ. Soc., Campinas, v. 23, n. 80, p. 368-385, 2002.

CARVALHO, N. R. Geographia do Brazil: a construção da nação nos livros didáticos de geografia da primeira República. 2012. 209 f. (Mestrado em Geografia) - Instituto de Geociências, Universidade Federal de Minas Gerais, Belo Horizonte, 2012.

CHERVEL, A. História das disciplinas escolares: reflexões sobre um campo de pesquisa. Teoria \& Educação, v. 2, p. 177-229, 1990.

EAGLETON, T. Ideologia: uma introdução. São Paulo: Editora UNESP: Boitempo, 1997. 380p.

FONSECA, S. G. Caminhos História Ensinada. Campinas: Papirus, 1995. 242p.

FONSECA, S.; DÂNGELO, N. A reformulação curricular para o ensino de História no $1^{\circ}$ grau Estado de Minas Gerais. Educação e Filosofia, Uberlândia, v. 3, n. 6, p. 241-245, 1989.

GOODSON, I. F. Currículo: Teoria e História. Petrópolis: Vozes, 1995. 144p.

GUIBERNAU, M. Nacionalismos: o estado nacional e o nacionalismo no século XX. Rio de Janeiro: Jorge Zahar, 1997. 188p.

HOBSBAWN, E. Nações e Nacionalismos desde 1780: Programa, mito e realidade. Rio de Janeiro: Paz e Terra, 2008. 230p.

; RANGER, T. A Invenção das tradições. Rio de Janeiro: Paz e Terra, 2008. 316p.

LACOSTE, Y. A Geografia: isso serve, em primeiro lugar, para fazer a guerra. Campinas: Papirus, 1993. 263p.

LAVILLE, C. A guerra das narrativas: debates e ilusões em torno do ensino de História. Revista Brasileira de História, São Paulo, v. 19, n. 38, p. 125-138, 1999.

LEMOS, M. C. Algumas considerações sobre a proposta curricular de geografia para as séries iniciais do estado de Minas Gerais. In: ENCONTRO ESTADUAL DE GEOGRAFIA DE MINAS GERAIS, 3.,1997, Belo Horizonte. Anais... Belo Horizonte: UFMG, 1997.

MINAS GERAIS. Secretaria de Estado da Educação. Programa de Geografia de $\mathbf{1}^{\mathbf{0}}$ a $\mathbf{2}^{\mathbf{o}}$ Grau (incluindo o programa de Formação Social e Política para o Ciclo Básico, $3^{\mathrm{a}}$ e $4^{\mathrm{a}}$ série). Belo Horizonte, 1987. 47p. 
MINAS GERAIS. Secretaria de Estado da Educação. Conteúdo Básico Comum de Geografia do Ensino Fundamental e Médio. Belo Horizonte, 2007. 68 p.

MORAES, A. C. R. Geografia e ideologia nos currículos de $1^{\circ}$ grau. In: BARRETTO, E. S. S. Os currículos do ensino fundamental para escolas brasileiras. Campinas: Autores Associados, 1998.

PEREIRA, M. H. F. Nova direita? Guerras de memória em tempos de Comissão da Verdade (20122014). Varia Historia, Belo Horizonte, v. 31, n. 57, p. 863-902, 2015.

PEREIRA, Raquel Maria Fontes do Amaral. Da geografia que se ensina à gênese da geografia moderna. Florianópolis: Ed. da UFSC, 1993. 131p.

ROCHA, G. O. R. da. A trajetória da disciplina geografia no currículo escolar brasileiro (1837 - 1942). 1994. 147 f. (Mestrado em Educação) - Programa de Pós-graduação em Supervisão e Currículo, Pontifícia Universidade Católica, São Paulo, 1994.

SILVA, E. Q. Discurso(s) acerca do trabalho presente nos livros didáticos de geografia (18891945): educação, estado e ideologia. 2015. 235 f. (Mestrado em Geografia) - Instituto de geociências, Universidade Federal de Minas Gerais, 2015.

THERBORN, G. La Ideologia del poder y el poder de La ideologia. Cidade do México: Siglo Veintiuno Editores, 1991. 101p.

TRAVERSO, E. Historia y memoria. Notas sobre un debate. In: FRANCO, M.; LEVÍN, F. Historia reciente. Perspectivas y desafíos para un campo en construcción. Buenos Aires: Paidós, $p$ 69-96, 2007.

VLACH, V. R. F. A propósito da ideologia do nacionalismo patriótico do discurso geográfico. In: CONGRESSO BRASILEIRO DE GEOGRÁFOS. 4., 1984, São Paulo. Anais... São Paulo: 1984. 